statistical programs to analyze a data base generated by a simulation model. Further experimentation will help us to determine the most effective way to integrate simulation into the psychology curriculum.

\section{REFERENCES}

Anderson, R. C., \& Faust, G. W. Educational psychology: The science of instruction and learning. New York: Dodd, Mead, 1973.

Holmes, J. D. S. New approaches to business simulations. In Proceedings of the 1972 conference on computers in the undergraduate curricula. Atlanta, Georgia: Southern Regional Education Board, 1972.

Johnson, R. DATACALL: A computer-based simulation game for teaching strategy in scientific research. In Proceedings of the 1971 conference on computers in the undergraduate curricula. Hanover, New Hampshire: Computer-oriented Materials for Undergraduate Teaching, 1971.

Main, D. Toward a future-oriented curriculum, American Psychologist, 1972, 27, 245-248.

\title{
Teaching research theory and application through on-line simulation
}

\author{
ARTHUR CROMER \\ University of Louisville, Louisville, Kentucky 40208
}

The development of the University of Louisville program for teaching experimental psychology and statistics through computer simulation techniques is described.

In the spring of 1971 , we began to replace the required undergraduate course in experimental psychology, which emphasized the theory of research, with a course that emphasized practice as well as theory. For purposes of education, we felt it necessary to provide a student with the opportunity for repeating an experiment many times with minor or even major changes. Most experiments that can be repeated easily are too simple to provide meaningful experience to the student, so the departmental computer was used to simulate the data collection portion of the experiment. The student was still responsible for reading the literature, seeking out meaningful research questions, planning the experiments, analyzing, and reporting the results. By combining these simulations with live experiments, where the primary emphasis was on the techniques necessary for running the experiments and collecting the data, a complete balanced coverage was provided for the entire range of research training.

This technique has been used successfully in about 22 sections (20 students each) of the experimental psychology course offered since the fall of 1971 at the University of Louisville, and at several other colleges and universities (Johnson, 1971; Main \& Head, 1971; Thurmond \& Cromer, 1972; Cromer, 1973; Hallenbeck \& Welch, 1974; Kissler, 1974; Stout, 1974). The students can learn to see not only questions that can be answered by a single experiment, but questions requiring a series of experiments encompassing an entire research program in order to take advantage of results obtained along the way. Some of the experimental models used in these classes have as few as 2 independent variables and 1 dependent variable, while others have 6 to 12 independent and 2 to 4 dependent variables. For example, in one simulation, there are 58,320 possible experiments that could be conducted; this does not include varying the number of Ss. This puts the student in a situation where he must formulate hypotheses in order to obtain results. With most of the computer models employed, the student would be completely lost without some idea of how to proceed intelligently.

It became evident that in order to teach this course effectively, the student must have a background in statistics. At the same time, the problems of motivating the nonquantitative students in sophomore statistics courses using only examples from a book had to be handled. Last year, a series of 22 programs covering the areas of general statistics, probability, correlation, and regression, nonparametrics, distributions, and analy sis of variance were developed to be used in teaching statistics. Some are intended as demonstrations, but most are intended to be used by the students in an on-line situation to aid in answering questions not otherwise answerable. For example, "For the two variables $\mathrm{X}$ and $Y$, given the following four pairs of numbers, choose another pair so that the two variables have a correlation of $-.50 \pm .02 . "$ Only when a student can instantly obtain a correlation can such a question be realistically 
asked for homework. By searching for a pair of values to satisfy the requirement, and observing the various effects that can be produced, a type of understanding of the relationships it.ulved in correlation is obtained that many of us attain only after years of experience in working with correlations (Cromer, 1973).

In the fall of 1972 , we planned a course to cover two semesters that combined the two separate courses. The plan was to have about 10 modules, each module covering experimental concepts, statistical concepts, text materials, and activities (such as film or video tape, computer or live demonstrations, etc.). The students would learn some statistics and then would have to apply these, selectively, to a real research project. Hopefully, these findings would motivate them to learn more statistics in order to plan more efficient experiments and better analyze their results. There are, of course, problems. The remainder of this paper will describe what has been done and some major plans.

One section of the combined course is being taught this fall at the University of Louisville, along with several traditional sections of statistics and experimental psychology. All classes are using the computer for simulations, but only the combined course is also using the statistics programs extensively. The computer terminals are available both during class, adjacent to the classroom, and outside of class at any terminal on campus.

All of the programs to support statistics have been put together in the form of an instructor's guide, with a brief description of input and output, and a program listing for each program. A similar instructor's guide is being prepared to enable the instructor to prepare his own experimental model and add it to our system with minimum inconvenience. At present, additional models covering arousal and night driving are being prepared; one on fear and sex has already been added. At present, the student guide is made available in the Campus Store, and instructor's guides are duplicated, as needed, within the department. Plans are being made to publish the student guide, containing the scenario for each model, and an instructor's guide to accompany it. This package, to be effective, should include some provision for getting the models running on any local computer. The models presently in use at the University of Louisville are written in BASIC and run on a Hewlett-Packard $2000 \mathrm{C}^{\prime}$. Some of the models were converted from FORTRAN and some were originally written in BASIC but converted to FORTRAN and now running under EXPERSIM (or MESS) at the University of Michigan and the Triangle Computer Facility in North Carolina. It is expected to provide versions of the University of Louisville system in both BASIC and FORTRAN for distribution and use along with the guides mentioned above.

There has been some emphasis put on the lack of a system in which the average instructor, or graduate student, without any programming knowledge, could prepare a simulation model that could be called up by other students as a simulated experiment. The preparing of such a system could open up to much more widespread use the routine use in classrooms of simulated models as another teaching aid, such as is being tried at the University of Louisville in a graduate perception class. We hope to have such a system operating by the spring of 1974 .

\section{REFERENCES}

Cromer, A. O. Teaching experimental psychology with on-line computers. Behavior Research Methods \& Instrumentation, $1973,5,195-197$.

Hallenbeck, C. E., \& Welch, R. B. Generalizing the problem definition step in the computer simulation of factorial experiments. Behavior Research Methods \& Instrumentation, $1974,111-121$.

Johnson, R. DATACALL: A computer-based simulation game for teaching strategy in scientific research. Proceedings of the Conference on Computers in the Undergraduate Curricula, Dartmouth, June 1971.

Kissler, G. R. Evaluation of computer-based laboratory simulation models to teach scientific research strategies. Behavior Research Methods \& Instrumentation, 1974, 6 , 124-126.

Main, D. B., \& Head, S. Computer simulations in the elementary psychological laboratory. Proceedings of the Conference on Computers in the Undergraduate Curricula, Dartmouth, June 1971.

Stout, R. L. Modeling and the Michigan Experimental Simulation Supervisor. Behavior Research Methods \& Instrumentation, 1974, 6, 121-123.

Thurmond, J. B., \& Cromer, A. O. Toward the optimal use of computer simulations in teaching scientific research strategy. Proceedings of the Conference on Computers in the Undergraduate Curricula, Atlanta, June 1972. 